\title{
Globalization of Markets Compels Changes in the Value Addition Chain of the Automotive Industry
}

\author{
Prof. Dr.-Ing. H. Schulz
}

Technical University of Darmstadt

Petersenstr. 30, 64287 Darmstadt, Germany

Keywords: OEM-suppliers, restructuration, value addition chain

\section{ABSTRACT}

The value addition chain of the automotive industries must change essentially. This demands new requirements to the suppliers and a total restructuration of the relationship between OEM and suppliers. 


\section{PRODUÇÃO}

\section{Com pet i t i o Characteristics in the Automotive Industry}

The industry of European automotive suppliers is subject to profound change. The driving force behind this change is primarily a growing worldwide competition among automobile manufacturers which essentially is characterized by the following aspects (Fig. 1):

1. Worldwide excessive capacities amounting to 10 to $15 \%$, and thus strong cost pressure

2. Reducing product life cycles, and thus the necessity of reducing product development times

3. Increased product variety due to individualization of demand

\section{Strategies of Automobile Manufacturers}

Increased competitive pressure compels to improve sales efficiency and to take far-reaching reorganization measures: Not only the in-house processes must be improved but also the entire value addition chains from raw material production to manufacturing the finished product.

The reason for the focus being on preparatory production steps is their high share in the total value addition for automobiles which, depending on the manufacturer, is comprised between 55 and $75 \%$, so that cost savings achieved by supplier management have a substantial impact on the overall cost situation. The essential strategies used by automobile manufacturers to achieve their material and economic objectives can be summarized as follows: strategies:

- Changes in value addition

1. Reduction of manufacturing depth

2. Reduction of development depth

- Changes in sourcing strategies:

1. Global sourcing to open up comparative cost benefits

2. Single sourcing, in particular for valuable and top quality parts 3

3. Systems sourcing

\section{New Requirements Made of Suppliers}

Today as in the future, the changed value addition and sourcing strategies of automobile manufacturers lead to increased performance requirements being made of suppliers.

Key success factors are:

1. comprehensive quality competence,

2 .globally competitive cost situation,

3. distinct production competence

4. high development competence

5. logistic competences 
The first two success factors are essentially knock-out criteria, i.e. they must be met by suppliers to be accepted among those who will be allowed to continue direct supplies to automobile manufacturers. Actual winners of the ousting competition will however only be those suppliers who clearly differentiate themselves from their competitors by fulfilling the competence items 3 to 5 .

\section{Con s e que n c es: Restructuration of the Value Addition Chain}

The intentions of German and European automobile manufacturers of using single and modular sourcing strategies to reduce the number of direct suppliers, from currently approx. 1000 to 1500 for each manufacturer to less than 400 , will result in the formation of a new supplier hierarchy (Fig. 2). At the top of this hierarchy will be the remaining direct suppliers (first-tier suppliers) who have completely fulfilled the changed requirements profile and now act as a sort of general contractors to supply ready-tomount modules direct to the automobile manufacturers. These first-tier suppliers are in turn supported by various suppliers who, due to restricted fulfilment of the requirement profile, merely attain the rank of second-tier suppliers who manufacture components for the modules. Only few of these component manufacturers will be able to manage keeping an independent position as innovative niche vendors in a direct suppliers relationship with the automobile manufacturers. These subsuppliers, who formerly used to be direct suppliers to the automobile manufacturers, in their turn purchase certain components for their products from other sub-suppliers (third-tier suppliers), who except for suppliers from low labour cost countries do as a rule not have direct contacts with automobile manufacturers any more.

For the European automotive industry, this scenario means an extreme change of the suppliers market: It is estimated that of the currently about $\mathbf{3 0 0 0}$ mostly independent medium-size suppliers only just 500 will survive; out of these, approx. one hundred will be direct suppliers, with half of them being supported by substantial participation from foreign countries.

In order to make the leap to becoming modular suppliers, international cooperations will be necessary in many cases, since on one hand the required know-how will not be completely available in a single company, and on the other this will permit to respond faster and more easily to the globalization of demand.

It is this capability to respond that will become more and more important as the automobile manufacturers will increasingly attempt to launch ,world cars" in the market. This requires international competence centres for development, production and logistics 


\section{PRODUÇÃO}

which today are available in few supplier companies only, so that the above mentioned cooperation will often provide the only chance of participating in the international systsems business.

\section{Conclusion}

The profile of a successful modular supplier will be as follows:

Both market requirements (Items 1 through 5, for achieving a critical mass and for creating adequate synergies between various customers) and financial requirements (Items 6 and 7 , for financing the necessary $R \& D$ requirements) as well as the aforementiond requirements (Item 8) must be fulfilled. In detail, this means:

1. Sales volume above 500 million US dollars

2. Supplies to several international customers

3. Presence in at least two regions of the triad

4. Regional market share above $15 \%$

5. First or second tier supplier

6. Adequate cash-flow

7. Profit on sales above $5 \%$

8. Fulfilment of all aforementioned requirements concerning quality capabilities, cost structure as well as competences in development, production and logistics. 
competition characteristics

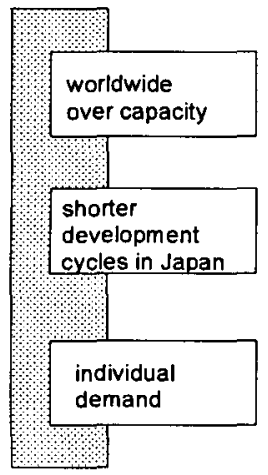

- too optimistic planning of the manufacturers

- high degree of market satisfaction in bigger markets

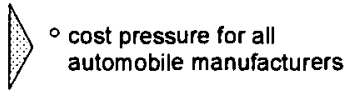

doubling the product range in Japan during the 80 s with constantly young products

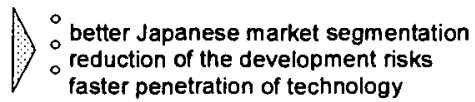

$\circ$

automobiles with "emotional

- additional benefit"

- better basic equipment more special options

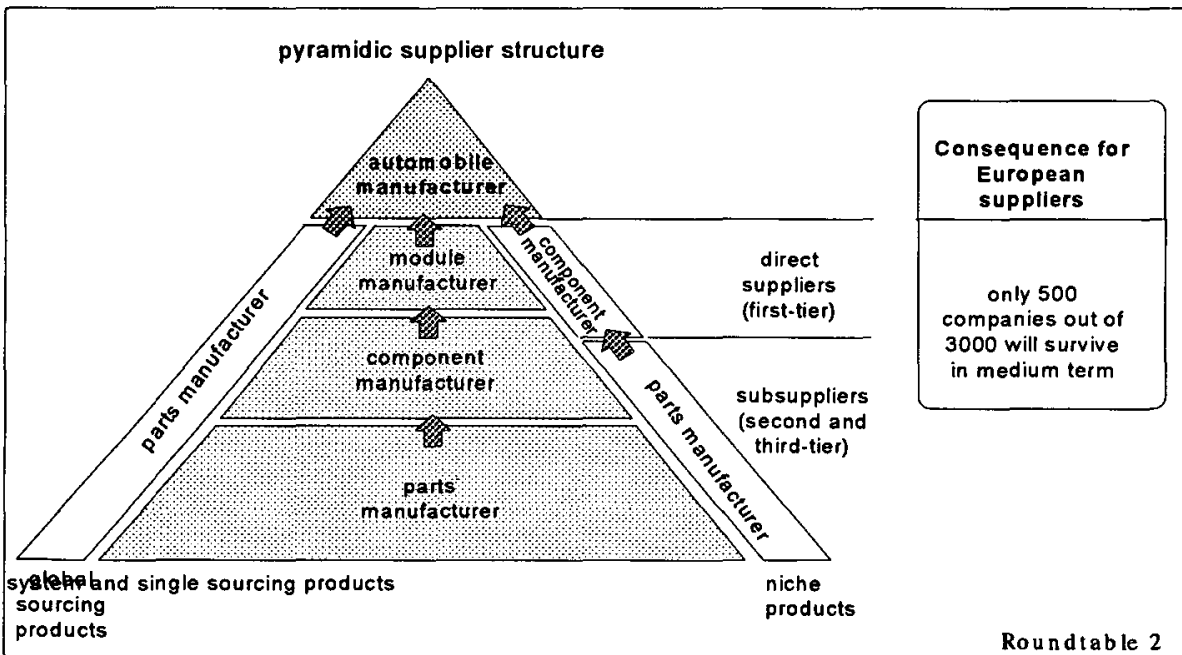

